\title{
Platformisation of Mobile Operators Business Model: A Proposition Using Design Science Approach and Grounded Theory Principles
}

\author{
Aladeen Y. R. Hmoud ${ }^{\mathrm{a} 1}$, Juhana Salim ${ }^{\mathrm{a} 2}$, Mohd Ridzwan Yaakub ${ }^{\mathrm{a} 3}$ \\ ${ }^{a}$ Center for Artificial Intelligence Technology, Faculty of Information Science and Technology, Universiti Kebangsaan Malaysia 43600 \\ Bangi, Selangor Darul Ehsan, Malaysia. \\ E-mail: ${ }^{1}$ aladeenh@yahoo.com, ${ }^{2}$ js@ukm.edu.my, ${ }^{3}$ ridzwanyaakub@ukm.edu.my
}

\begin{abstract}
Mobile network operators (MNOs) business models (BM) are under pressure due to their lesser capability of introducing superior values to their customers in the mobile ecosystem. However, recent research efforts in developing new BM advocate twosided BM that encompasses the diversity of MNO's activities and capabilities. As a result, a new multidisciplinary service-based twosided BM needs to be developed that incorporates these activities and skills. The small body of the extant literature on the subject suggests that it may be possible to enhance MNOs' BM by combining contemporary information technology tools with managerial design principles and concepts. This study designs a two-sided mobile advertising BM to investigate the application of a big datadriven BM to transform MNOs' current one-sided BMs to two-sided ones. To accomplish this, it combines the design science research methodology (DSR), which aims to create a problem-solving artifact for real-world problems, and the grounded theory approach, which aims to develop substantive theory and increase the rigor of the design process. The initial BM was proposed using deductive and adductive reasoning from academic and grey literature. The results of this study have shown that the new BM can enhance their revenue streams and competitive edge. This study identified that successful BM should be built on established MNOs core competencies and business activities. This study showed the applicability of two-sided theory and big data-driven tools and technologies to create new superior value propositions to both advertisers and end-users and thus innovative BMs for MNOs. The paper concludes with the fundamental requirements to build a data-driven two-sided BM.
\end{abstract}

Keywords - two-sided BM; big data; design science; data-driven services; mobile advertising.

\section{INTRODUCTION}

The mobile ecosystem is now immensely different from how it was just 10 or 20 years ago. The explosion of mobile technology is evident in the ubiquity of mobile platforms, mobile sensors, application stores, and mobile applications (or simply, apps). This explosion has changed how businesses operate and how competitive the mobile ecosystem has become. This explosion was a turning point in the mobile sector, enhancing some actors' roles in this ecosystem, such as mobile developers, and inhibiting others' roles, such as telecom and mobile network operators (MNOs).

A dramatic wave that has affected the BMs of MNOs encouraged practitioners and scholars to investigate its causes and reconsider the structure of the current business environment. In essence, the findings of practitioners' reports and academic publications indicate unanimously that the MNOs represent a paradox. MNOs are not only providers of their digital and value-added services, but they are also enablers for other sectors because they offer connectivity infrastructure for them. However, the market studies and experts' speculations indicate that the revenue streams for MNOs from traditional services will decrease despite the expected increase in numbers of digital consumers in the next few years and the resulting increase in demand for connectivity services. The major threat causing this decrease in revenue can be identified as an influx of new digital natives or big players, and this will continue as they penetrate the mobile ecosystem with their innovative BMs and supersede the role of MNOs by introducing their core services to business and individual consumers more conveniently and satisfactorily [1]-[3]. These attract organizations' and customers' attention for their ability to collect user data that is sensitive to context and time at the same time as the need for this kind of data has risen from businesses' and customers' increasingly dynamic environment [4]-[6].

In response to these industrial problems, several studies have been conducted that consider the options that can be explored in new dynamic ecosystems. What the majority of these studies have found is that the success of all the key players' initiatives in this ecosystem can be attributed to the platform or platformisation of BMs [1]-[3]. In effect, they 
usually mediate between different sides of the market (e.g., advertisers, customers, developers) [2], [7], [8]. This area is where the MNOs have failed to catch up: in contrast to the successful key players, they have lesser capabilities in providing new value propositions and incentives for different sides of the market to achieve the two-sided platform [3], [8].

Though many studies have been conducted on this problem, few studies have expanded to introduce viable solutions such as mobile advertising [9], [10], big data tools [11] and two-sided market or platform [2], [12]. The discussion for applying two-sided market theory in the MNO $\mathrm{BM}$ take place for several years, but unfortunately, few works have been conducted to explore the multiple opportunities and possible avenues in the business [2], [12]. Furthermore, the two-sided market theory has been studied in other industries; the focus of works conducted within a mobile ecosystem has centered on over the top players (OTTs). Unfortunately, the MNOs BM thinking as per twosided market theory's applicability in academia is very few and limited to speculations from experts and white papers or limited to exploring application developers as one side of the market while overlooking other sides such as advertisers, retailers, government entities and so on [1], [2]. Based on this research gap and industrial problem, there is a need for an interdisciplinary study to address the applicability of opportunity of the two-sided BM to one of the most important retail market sectors in the world. Hence, this paper will explore opportunities and challenges to apply two-sided market theory by MNOs by exploring other prospected sides of the market and identifying the related technologies and design principles to achieve this aim. This research will apply dual method firstly, address this gap by synthesizing and analyzing literature to extract a set of opportunities and design principles to MNOs, secondly to propose a two-sided platform based on these findings.

\section{MATERIALS AND METHOD}

\section{A. Selection of Research Method}

This research aims in designing solution-based artifact for the existing organizational problem. In other words, it is about identifying the central concepts (constructs of the solution) and mapping the relationships between these concepts to express the business logic of the organization in a way that enables them to seize a technological opportunity according to BM definition [13]. To achieve this, the design science research methodology (DSR) has been chosen to address the research problem, and help to achieve the goal of this study, which is to change this inferior competitive state into an advantageous more desirable one. This approach provides the researcher with the ability to integrate any suitable quantitative or qualitative strategies throughout the study's course of activities [14], [15]. To explore the current opportunities and challenges for MNOs and identify the gap in the current literature, we used a thematic analysis applied to the extant literature. We followed a research design suggested [16], makes use of constant comparisons for similarities and differences, to achieve precision and consistency. However, literature analysis are divided into mature and emerging topics [17]. As the current research can be considered as an emerging topic, we follow their suggestion that the emerging topic literature review can be short and concentrate on the fresh theoretical foundations proposed in developing a conceptual model. The criteria of the literature review process are listed in Table I.

The artefact resulting from DSR can be constructs, model, method and instantiation or a combination of them [18]. In this phase of our research, the focus will be on extracting the main constructs of the solution followed by building the initial model.

TABLE I

LITERATURE REVIEW SELECTION CRITERIA

\begin{tabular}{|l|l|}
\hline Criteria & Details \\
\hline Search & - Research database \\
& - Open search engines \\
& - Reliable websites \\
\hline Keywords & - Mobile operators \\
& - Mobile ecosystem \\
& - Business model \\
& - Data-driven business model \\
& - Big data \\
& - Two-sided business model \\
& - Platformisation \\
\hline Inclusion & - Industrial reports \\
& - Academic paper \\
& - books \\
\hline
\end{tabular}

The methods used were driven from acceptable MIS research methodologies identified [19] who identified thirteen different methodologies and ranked them by their popularity. From these thirteen, five acceptable methods have been chosen based on current study objectives and phase. Table II shows build activities for each output, and the associated methods applied.

TABLE II

BUILD ACTIVITIES FOR CURRENT RESEARCH

\begin{tabular}{|l|l|l|}
\hline Output & Build & How to build? \\
\hline Constructs & $\begin{array}{l}\text { Find the basic components of the } \\
\text { proposed model } \\
\text { (Building blocks) } \\
\text { (Mobile advertising, two-sided } \\
\text { platform, big data) } \\
\text { Conceptual framework }\end{array}$ & $\begin{array}{l}\text { Expert's speculation } \\
\text { Frameworks and } \\
\text { conceptual models } \\
\text { Literature analysis } \\
\text { Industrial reports }\end{array}$ \\
\hline Model & $\begin{array}{l}\text { Identify the relationship between the } \\
\text { components } \\
\text { Identify the architectural design } \\
\text { requirements }\end{array}$ & $\begin{array}{l}\text { Frameworks and } \\
\text { conceptual models } \\
\text { Literature analysis } \\
\text { Expert's speculation }\end{array}$ \\
\hline
\end{tabular}

Finally, to extract the themes from the literature, we applied a grounded theory approach principles using open, axial, and selective coding as following (i) the main constructs represent the selective codes, (ii) the subconstruct represents axial codes (iii) and the design principles represent the open codes [20], [21]. The grounded theory techniques are essential for exposing generated analytical insights to rigorous scrutiny and construction theory whereby all kinds of "slices" of data (e.g., primary data, such as qualitative interviews, secondary data such as documentation and extant literature) are applied to attain higher levels of abstraction and advanced conceptualization [22]. 


\section{B. Development of Proposed BM Based on Literature and Practice (Coding)}

The analysis of related works in different relevant disciplines was conducted in this study as a warrant for three objectives; (i) identify the gap in each construct to ensure that the solution is new, according to DSR principles (ii) identify the possible opportunities, challenges, and design principles for new artifact (iii) build the new artefact on the basis of existing knowledge (kernel theories), so that the solution is derived from a rigorous base. Thus this part will cover four sections according to themes in related literature, namely MNOs managerial design principles, two-sided market, mobile advertising, big-data-driven BM.

1) MNOs Managerial Design Principles: Through our review of mobile ecosystem BM works, scholars have aimed to analyses and understand the complex structures and design of BM of different players of this ecosystem. Several scholars address the issue of the mobile ecosystem BM to suggest possible solutions to MNOs and other players, which is relevant for this study. Most of these works have concentrated on developing a set of design principles and methodology to reinvent the BM of MNOs [23], [27]. Despite the substantial base that these works have brought to this field, these works have neglected the technological innovation aspect. However, the BM literature, in general, faces a gap with using technological innovation and on the other hand, the technological innovation scholars overlook the role of BM in deploying this innovation in organizational context model [28], [29].

The current study explored the second option and analyzed what the extant literature has proposed, related to this issue. The central construct of MNOs BM was used to guide the analysis, which was divided, into three categories: general findings, challenges for MNOs, and opportunities for them. A sample of these findings is presented in Table III, to show how the themes emerged based on valid results.

TABLE III

MANAGERIAL DESIGN PRINCIPLES FOR MNO'S BM BASED ON LITERATURE THEMATIC ANALYSIS

\begin{tabular}{|l|l|l|}
\hline $\begin{array}{l}\text { MNOs BM Managerial and } \\
\text { Design Perspectives (sub- } \\
\text { constructs) }\end{array}$ & Main Findings and recommendations (Design Principles) \\
\hline $\begin{array}{l}\text { Build services based on BM } \\
\text { logic and BMI }\end{array}$ & $\begin{array}{l}\text { Any successful mobile service must be created with a BM in mind. A venture and innovation of BM are an } \\
\text { inevitable business decision to consider as a way to sustain the competitive position. Adapt their new BM to } \\
\text { their core competencies. }\end{array}$ & $\begin{array}{l}\text { Supporting } \\
\text { [23]-[27], } \\
\text { [31] }\end{array}$ \\
\hline $\begin{array}{l}\text { Exploit new technologies and } \\
\text { opportunities }\end{array}$ & $\begin{array}{l}\text { Adapt to new customers expectation and demands. Seizing the new opportunities based on organization core } \\
\text { competencies. New BMs based on current technologies. Convert new technology to new customer value } \\
\text { propositions. }\end{array}$ \\
\hline Platformisation of BM & $\begin{array}{l}\text { Platformisation of BM is the new trend for successful players in the ecosystem. MNOs should adopt a } \\
\text { platform mindset. Creating value and innovation using technological platforms. The transition between the } \\
\text { value chain and value network. The design of successful value network is an essential element to innovate } \\
\text { the BM. Create services platforms. }\end{array}$ \\
\hline [2], [7], [12], \\
[33]-[35]
\end{tabular}

While the early focus of studying BM in this field was in conceptualizing and BM design, the latest focus is on the tooling of design and further integration of $\mathrm{BM}$ research and IS research [30], where the practical solution is missing. Noticeably, the major findings of most of the literature have shown a shift of most player towards the platfomrisation of their BMs. Therefore, the question raised in this study is what the platformisation opportunities are for MNOs, and how these opportunities are related to their core competencies. The answers to these questions are covered in the next sections.

2) Two-sided Market and Platforms: In various industries, platforms host two or more parties that use the platform to interact with one another for their particular purpose in a mutually beneficial way for both parties and for the focal firm that owns the platform [36]. Academic research on this phenomenon can be divided into two streams. The first is to explore the nature of these changes, and several papers have been published examining the structure of the mobile ecosystem, the causes of power turnover, and the possible avenues for each player to consider within the ecosystem [9], [31], [37]-[39]. The second, to propose solutions for MNOs as the most negatively affected player, however, has received very little attention [1], [2], [12].

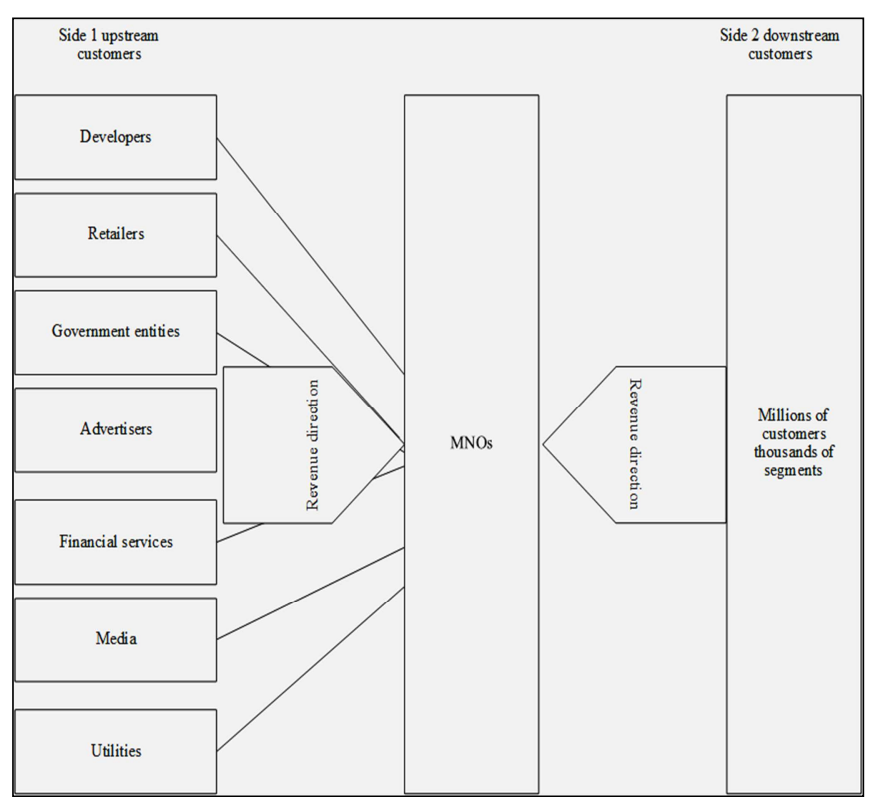

Fig. 1 Potential Sides of Two-sided Platform for MNO Source: Own Representation Based on [40]

Nevertheless, both streams reach the common conclusion that the MNOs are no longer able to compete in the application development arena. While the few academic studies that tried to suggest solutions were focused on mobile application development. The industry research and 
white papers, however, speculate that MNOs could embrace other areas and engage with different parties to form new platforms. Thus, the question arises here what other sides that the MNOs can explore to form a new platform based on two-sided market theory. To answer this question that the MNO operate between different entities and end-users [40].

Fig.1 shows some business entities who represent the upstream customers and end-users; and represent the downstream customer of potential MNOs platform.

\section{3) Mobile Advertising Platform}

Early works that tried to propose solutions for mobile operators were concentrated on advertising as a base to build a BM [9], [10], [41] though these studies may be considered outdated in this industry characterized by high turbulence. These works have documented the importance of mobile advertising as a potential revenue stream for MNOs to sustain their BMs. However, most recent industrial studies have reflected that there is a big opportunity for mobile operators to leverage on mobile advertising, as a revenue stream in the next coming years [42], [43]. However, the mobile operators are struggling, as some stakeholders are not satisfied with the advertising services in their current form, where some of their needs are overlooked [44].

Despite the scarcity and datedness of academic studies conducted to propose a solution for MNOs, the nonacademic publications revealed that mobile advertising is still achieving high potential, as we mentioned earlier. Therefore, these studies can contribute to the base of designing a BM that adopts mobile advertising. That said, we conducted a thematic analysis to extract the main principles from them to aid in designing our artifact. The central construct, mobile advertising, was used to guide the analysis, which was divided, into three categories: general findings, challenges for MNOs, and opportunities for them. A sample of these findings is presented in Table IV to show how the themes emerged based on valid results.

TABLE IV

MobiLe AdVERTISING Design Principles FOR MNO BASED on LITERATURE THEMATIC ANALYSIS

\begin{tabular}{|c|c|c|}
\hline $\begin{array}{l}\text { Mobile advertising as a } \\
\text { solution for MNOs issues } \\
\text { (sub-constructs) }\end{array}$ & Main Findings and recommendations (Design Principles) & $\begin{array}{l}\text { Supporting } \\
\text { Literature }\end{array}$ \\
\hline Opportunities and Challenges & $\begin{array}{l}\text { - The mobile advertising applications have high potential. } \\
\text { - } \quad \text { Context-aware mobile advertising is beneficial to advertisers and MNOs. } \\
\text { - } \text { Mobile advertising creates many opportunities such as; enhancing organizational innovativeness, } \\
\text { strengthening competitive advantages, and creating value-added mobile ad services. } \\
\text { - } \quad \text { Additional competition with LBA app developers. } \\
\text { - Uncertainty about LBA effectiveness and ROI from advertisers }\end{array}$ & [9], [42], [44]-[47] \\
\hline Requirements & $\begin{array}{l}\text { - Advertisers need feedback apparatus about their advertising activities. } \\
\text { - Time convenience, security, and privacy have a high priority for end-users. } \\
\text { - Both end-users and advertisers need monetary and information incentives to participate in mobile } \\
\text { advertising platforms effectively }\end{array}$ & {$[10],[44],[48]$} \\
\hline
\end{tabular}

In summary, the mobile advertising still has significant potential, but in case of MNOs, the SMS and location-based advertising (LBA) current models suffer from some obstacles that hinder them from reaching their maximum potential as industrial reports indicated. The advertisers' need data about their advertising activities to help them evaluate and assess their investments as compared to the dominated parties such as Google, Facebook, and others [45]. On the other side, end-users have an overwhelming wave of pushed ads that effect largely their privacy and intrude their devices and time. Also, the end-users need effective incentives mechanism to attract them to adopt these models and be loyal to them.

Thus, a proper strategy is required to overcome this and reach a trade-off between advertisers and end-users interests, and hence, adequate incentives are required to make this more attractive and convenient. Several questions have arisen from the past discussion, and they include: First, what available feedback tools can MNOs create for advertisers to attract them to advertise more while also increasing end-user adoption with a proper incentives mechanism? Second, how to protect end-users' privacy, data, and make mobile advertising appealing and more time convenient? In the context of the BM, this means how to create value with superior value propositions to involved parties.
4) MNOs and Big Data: Many scholars have made arguments that big data would be a key basis for competition [49]. Consequently, several research questions stem from this phenomenon, such as; what kind of BMs can firms deploy to leverage big data? What are the industries and organizations that have the most potential to use big data? What is the associated risk of doing that? What is the suitable technological platform to deploy and thus develop a $\mathrm{BM}$ upon it? What are the design principles for building this kind of BM? and many other questions.

Despite the importance of big data in the telecommunications industry as an industrial research tool, sponsored white papers have shown that there is a lack of studies that address this important sector [48]. The MNOs and telecommunication sector have been addressed partially in general-purpose studies [43], [50] or, in the form of conference paper [11], white papers, consulting reports, and industrial reports. Therefore, there is a need for the study to address the big data-driven BM type, as stated by [48] in their review paper. Nevertheless, few studies were identified as relevant to this construct, and the design principles were extracted from them to advise the artifact design. The themes are presented in Table II.

The innovation can be achieved by following a successful $\mathrm{BM}$, or so-called analogies of others, even if they belong to other industries[51], [52]. Applying other solutions from 
another field (exaptation) can be considered innovative and contribute to research as well [53]. Another important conclusion from those companies that have succeeded in selling data and analytics are those who (i) established a prior relationship with their business partners for ordinary business practices. (ii) Introduce the data and analytics services to them with pre-specified purposes [43], [50], [54].

In sum, the companies that are seeking to expand their original $\mathrm{BM}$ to include big data should explore current business partners and their needs [50], [54]; this makes the research more focused and opportunities easy to detect. This conclusion is compatible with [55], who stated that the platformisation for established companies is restricted to the current value chain and is customer based. As in the twosided BM (platforms), the concept of introducing proper incentives to lure the participants to join applies to DDBMs, and in most cases, data are captured from end-users and individuals [11]. These entities require something in exchange for their data, and not only that but also the privacy and other related regulations issues should be considered to ensure their data security [50]. The external deployment of big data to design a new BM has high rewards for organizations if they exploit it according to warranties provided previously. Real business cases are required to be explored by scholars to provide the MNOs with prospected avenues to exploit.

TABLE V

BIG DDBM DESIGN PRINCIPLES FOR MNO BASED ON LITERATURE THEMATIC ANALYSIS

\begin{tabular}{|c|c|c|}
\hline $\begin{array}{l}\text { Data-driven BM for } \\
\text { MNOs }\end{array}$ & Main Findings and recommendations (Design Principles) & $\begin{array}{l}\text { Supporting } \\
\text { Literature }\end{array}$ \\
\hline Opportunities & $\begin{array}{l}\text { - External deployment of big data to design new BM has high potential. } \\
\text { - Crowd data are precious to create value propositions and therefore DDBM. } \\
\text { - } \quad \text { Analogies of other industries BM can be leveraged by MNOs based on their core competencies. } \\
\text { - Aggregate data has great potential to create DDBM and avoid privacy and regulation issues. } \\
\text { - } \quad \text { Brand extension considered advantageous to MNOs to sustain their competitive position. } \\
\text { The mobile phone sensing to collect users' data is advantageous due to increased coverage, on-demand } \\
\text { sensing, and social value. }\end{array}$ & $\begin{array}{l}{[11],[50],} \\
{[54],[56]-} \\
{[58]}\end{array}$ \\
\hline Challenges & $\begin{array}{l}\text { - Not all required data is within reach of MNOs } \\
\text { - Three inhibitors for data-driven implementation according to their significance namely cultural issues, } \\
\text { perceived value or benefits of DDBM, data quality and integrity. } \\
\text { - Speed is a central factor for value creation from big data. } \\
\text { Privacy and security. }\end{array}$ & $\begin{array}{l}\text { [43],[57], } \\
{[59]}\end{array}$ \\
\hline Requirements & $\begin{array}{l}\text { - Purposeful analysis of raw data. } \\
\text { - } \quad \text { PDBM for established companies is assembled on their current value chain and customers base. } \\
\text { Proper incentives to users }\end{array}$ & $\begin{array}{l}\text { [11], [43], } \\
{[50],[54]}\end{array}$ \\
\hline
\end{tabular}

\section{Theoretical Framework}

By DSR and to answer the questions raised in the previous sections, a theoretical lens is needed to build the initial model of the proposed artifact. In this and subsections, the extant literature is investigated to identify the available theories, tools, and models to direct the designing process for the components of the two-sided DDBM. Hence, these section and subsections present the theoretical framework from the extant literature to delineate a research path to develop and design the artifact.

1) Business Model and Business Model Innovation: The concept and theory of BM are discussed in several disciplines and for many purposes. In the context of this study, the BM and BMI concepts and theories are disclosed to clarify the role of it in creating competitive advantage and new service-based BM. In the literature, many definitions of BMs, and several studies have compared and discussed various definitions and lists of BM components [60]-[61]. In this study, we adopt a definition that has frequently been adopted by scholars in recent years, and this is that a BM describes how the value is created, delivered, and captured. Simply defined, the BM main purpose is in defining how the business provides its customer with value, persuades customers to pay for it, and profits from the payment [62]. Since 2007, changes in markets have shown the value of innovative BMs and completely inverted the dominant logic of whole industries. For instance, Apple's new place in the music industry is a frequently cited example [63]. Therefore, a new concept BM innovation (BMI) has emerged and received a considerable research interest. In this regard, a BMI is a new way of creating and capturing value by changing one or many parts of the BM [28], [64]. For instance, established firms realize that the innovation of their products and processes is not enough to remain competitive in the modern dynamic economy [65]. Thus, efforts in innovation need also to be expanded to comprise the company's governing logic of doing business, thus the BM itself. By doing that, new BMs have the potential to uncover market possibilities in technological innovation [51], push competitive advantage [62], and make the firm develop and be profitable [66].

2) Two-Sided DDBM Relevant Design Tools and Theories (Kernel Theories): After defining the BM and BMI concepts, it is necessary to investigate the existing literature to find available tools and frameworks that can inform the artifact design process. In the present study, the issues under scrutiny are (i) BM framework that can define the major components of the artifact and inform data analysis process. (ii) The DDBM framework that advises the selection of artifact components concerning data types, analysis tools, data sources, and others. In the following sections, the available BM and BMI literature that can advise the design of two-sided BM were examined. Similarly, the data-driven, revenue models, and data-infused BMs related works were reviewed. 
To this end, it was found out that many frameworks were developed as a theoretical foundation to build, evaluate, and test BMs. In this study, a magic triangle archetype of the BM [52], [67] is adopted as a theoretical lens to discuss the four components of BM. Whereas, a DDBM blueprint [43], [68] has been chosen as a conceptual guide in the building of related data components. The justification and explanation of the selection of these frameworks and associated tools is discussed in the next subsections.

3) Design Components of Business Model: Despite the lack of agreed BM definition, several frameworks have been proposed to build and evaluate the BM. However, a dense, but reasonably exhaustive, list of components can be found in [52], [67]. Their scheme resembles the most cited one work in BM developed [13]. Nevertheless, it is divided into four main question categories of "what," "who," "how," and "why." Generally, the groups of activities corresponding to these headings are what the overarching value proposition is, the customer segments to whom the value proposition is targeted, what the company's value delivery methods are, what value chain configuration is necessary to develop and deliver the offering, what additional resources are required for maintaining a central position in the value chain, and how the firm's internal organization and processes create and maintain connections among the other parts of the model function.

4) Data-Driven Business Model (DDBM): The main role of Big data analytics (BDA) is to provide firms with the recognition of what has happened, what is happening now, what is likely to happen next, and what needs to be done to produce more optimal results [56]. BDA presents insights by uncovering hidden patterns to enhance decision making, make more real-time decisions, support innovation, and improve a firm's performance [69].

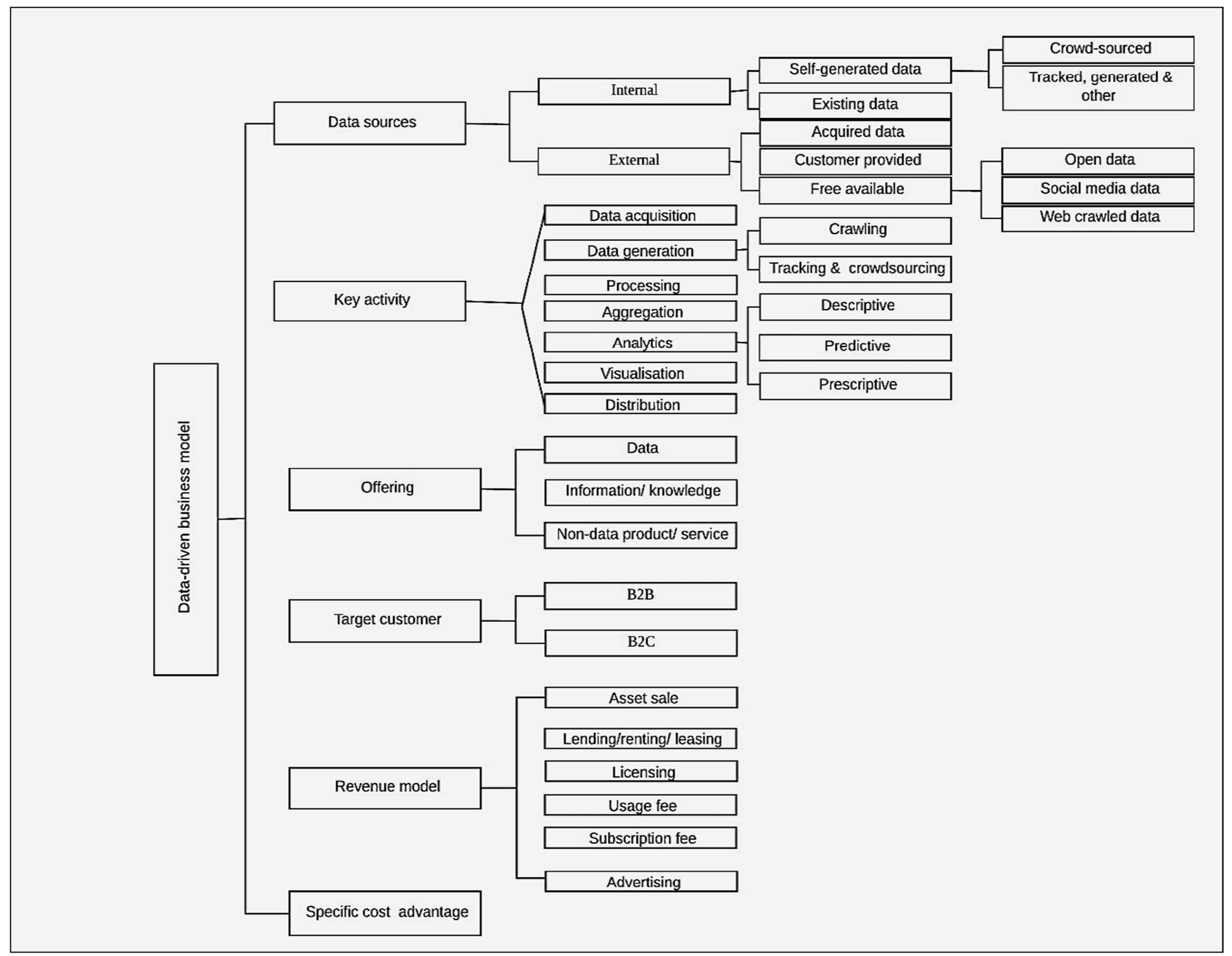

Fig. 2 the data-driven business-model framework (Source: [76])

However, how to leverage BM by exploiting your new valuable assets of big data is a new emerging trend in the field of BMs and related literature. Here, the concept of the data-driven BM (DDBM) has received more attention in research in big data contexts. Moreover, the concept's early emergence found in research in the form of sponsored white papers from and from solutions vendors which have contributed to the attention drive [68]. Notably, the focus of these works was on the big data's role in the value creation 
process, where the companies may explore to enhance or create a BM.

In academia, the research on the data-driven $\mathrm{BM}$ is limited. For example, a study [68] proposed DDBM taxonomy framework. While the study is conducted based on a sample of start-up companies, [68] have argued that this taxonomy can also be applied to established companies.

The DDBM framework, demonstrated in Fig. 3, is a basis for the analysis and clustering of BMs. These dimensions and various features may guide practitioners in ways to form a BM for their venture. The framework enables the identification and evaluation of available possible data sources to be used in the DDBM. Additionally, it provides exhaustive sets of potential core activities and revenue models. In the same vein, the extended study was conducted [43] to validate the framework [68] on established firms. They found that this framework is valid for established firms and that it provides a step-by-step process for them to develop their own data-driven BMs. Eventually, the structures enable organizations to build their DDBM, specialized to their business and environment. Though the framework has fruitful contributions, we argue that sector and organizational oriented studies are necessary to align it with its context, environment, and aims.

DDBM is defined as "a BM that relies on data as a key resource" [68]. Data is fundamental to a DDBM" [43]. Data should be central to the business [70]." These definitions are rather simple and differentiate BMs on their use of data or not. However, there is insufficient understanding of how these BMs function and how businesses can transition into them. Therefore, a more complex perspective on DDBM is proposed [71]. According to their account, there is no DDBM per se; instead, there is a continuum of options for how to provide data-driven service. Hence, there is a smooth transition between BMs that use little data and those that enrich all areas of its BM with data analysis [71]. Therefore, existing data or new data can be used to either create new BMs or enhance existing ones [72]. In the latter case, either the value creation, the value proposition or the value capturing or combinations of these can be improved by data [71] that identify five separate patterns where using data might change the BM. The main aim of their research is how using data and applying analytics may trigger BMI. They identified five patterns, namely; I. Data-Infused Value Creation, II. Data-Infused Value Capturing, III. Data-Infused Value Proposition via Creation, IV. Data-Infused Value Proposition via Capturing, and V. New Data-Infused Business Model. They argue that the identified patterns would guide practitioners in how to utilize (big) data and analytics, especially those still underutilized for innovation.

The identified patterns were based on the three main components of BM: value creation, value capture, and value proposition as the main driver of value creation. Their study found that while over $70 \%$ of analyzed cases at least briefly consider value creation or value capturing (patterns I, II), a value proposition infused with data is still rare. Therefore, Davenport's "Analytics 3.0" phase, where data-driven changes appear in the offer to the customer has not happened yet for the majority of enterprises [73]. In addition to infusing the current core BM with data (pattern III and IV), companies may also make use of data and analytics to formulate entirely new BMs (pattern V).

To conclude, the framework developed by [68] and validated by [43] was deployed in this study to delineate the path for designing the proposed BM (artifact). The six questions that each organization needs to answer during the design and development of DDBM are (i) Target outcome: What is it we trying to accomplish? (ii) Offering: What is our desired offering? (iii) Data Source: What data do we need and from where are we going to acquire it? (iv) Key Activities: How are we going to utilize this data? (v) Revenue Model: How can we monetize it? (vi) Inhibitors: What are the obstacles to us accomplishing our goal? In this study, all these questions are answered in the result and discussion section, where the justification of each selection is provided based on early extracted arguments. Hence, in the next sections, all the arisen questions in the current study guided the development of the initial artifact. The datainfused BM pattern [71] will also be used to clarify what components of BM infused are and how. Finally, the revenue models proposed [68], will be thoroughly analyzed to select the most suitable for our artifact [74].

\section{RESULTS AND DISCUSSION}

In this section, the result of this work is presented. Firstly, we show how the adapted framework applied to the current work and what the proposed premises are. Secondly, we explain who the proposed model is fit to data-driven BM frameworks available in the literature. Thirdly, we developed the architectural requirements of a two-sided platform as a theoretical contribution to build similar artifacts.

\section{A. Components of the Business Model Framework}

The representation of the four dimensions ("Who," "What," "Why," "How") as initial propositions is elucidated [52], [67]. The three groups of participants in a platform ecosystem-platform owners, advertisers, and end-usershave unique needs and motivations for participating in it. Therefore, a platform must uniquely appeal to each group in how it aligns with their interests relative to a product or service. To be sustainable, a platform-based BM must also satisfy their needs better than alternative BM [75].

Additionally, we presented how the initial BM has been proposed. The conceptual representation of initial BM (artifact) is depicted in Fig. 4. This model seeks to deploy a two-sided BM strategy, by identifying the potential two sides that could form it, as well as the underlying technologies and tools that MNOs need to build such a platform.

As we mentioned previously that applications developers are no longer can be considered as potential prospects to form a new platform, therefore, we can argue that the promising avenues to accomplish this are mobile advertising combined with big data tools and technologies [3], [57]. The argument was made based on three premises (i) the industry report that indicated that the mobile advertising still has high potential and a vast amount of money to exploit (ii) all other sides have activities in the advertising area (iii) Big data analytics ability to provide marketing insights for different organizations. Thus, the constructs of the initial model are a 
mobile advertising platform that provides advertisers with application interaction and spatiotemporal data on customers, to enable market segmentation and targeting as a benefit, by using big data tools and data analytics as a service. Winning customer propositions with a proper incentive mechanism to encourage ordinary mobile users to adopt the platform. As this represents the abstract conceptualization of the artifact, the granular level of details is elucidated in the next section.

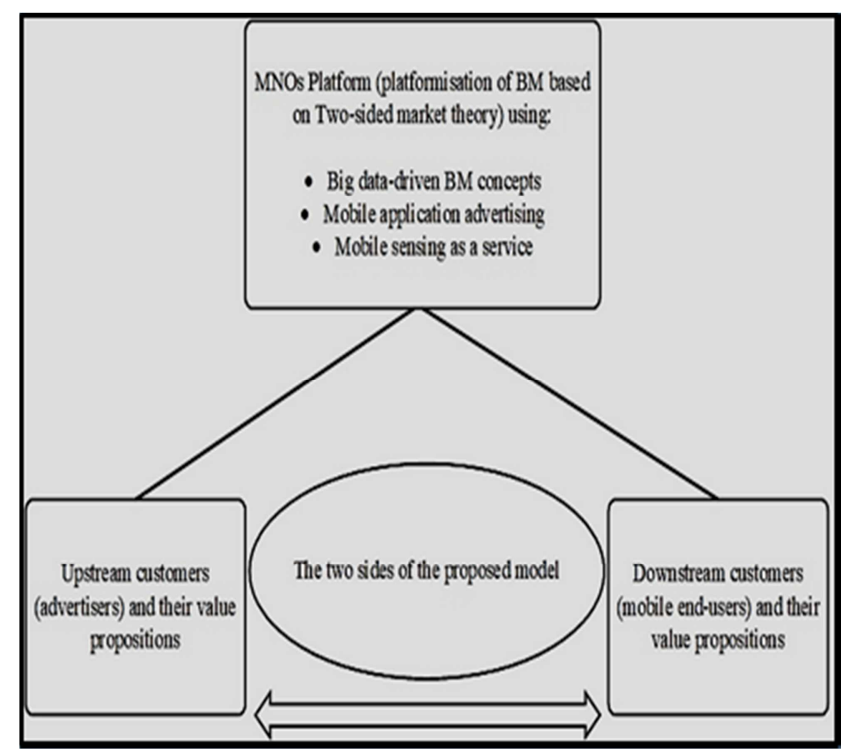

Fig. 3 Proposed conceptual two-sided BM for MNOs

\section{B. Data-Driven Business Model Components}

The artifact first iteration is developed with the guidance provided by DDBM framework, [68] and by answering the [43] blueprint six questions as follow:

1) Target Outcome: What are We Trying to Achieve?) [42] stated that any organization should set beforehand, the primary goal of constructing a DDBM. As in the problem explication, the major problem persisted for MNOs is the decreasing power within the mobile ecosystem, which led to losing their competitive position. Hence, the new DDBM in this study is a way to expand their business activities towards earning a new market share and revenue, based on their core competencies such as strong customer relationship and well-established business relationships, with various business entities.

2) Offering: What is Our Desired Offering? It is documented that for the established organizations [42], the principal aim of creating DDBM is to enhance existing service by data or add new offering for their line, as the majority have multiple offerings. By doing this, they introduce new value propositions for their customers, which is a value provided to their customers with new offerings. Moreover, they stated that the data or information (analytics) could be the offering (value proposition) by themselves or attached to non-data service or product to elevate the customer value proposition. For instance, they found that the telecommunication sector has a significant deployment of data as an offering, which was at $50 \%$ of their total deployment of data on their business. In the current artifact, the value proposition is a new offering of data analytics services attached to existing advertising services that can enhance this service and generate new data services alike. Concurrently, the target groups of the customer should be identified at this stage. The general classification is divided into three categories [68], [76], namely B2C, B2B, and C2C where, in many cases, organizations could target businesses and individual consumers [43]. Ultimately, we can conclude that the mobile advertising has strong prospects, but that the issue that endured in LBA is the lack of a shared platform where the MNOs, as platform providers, can create segregated advertising for consumers. This absence of a shared platform prevents advertisers from directly retrieving consumer information to devise insights, measure the actual ROI, and offer consumers relevant insights. Additionally, factors other than location contribute to the consumer perception towards LBA. Therefore, an advertising BM that fulfills these requirements is needed to raise the success potential, whereas the multi-sided platform is of great benefit to overcome the persistent problems with segregation [44].

In the proposed artifact, the $\mathrm{B} 2 \mathrm{C}$ model is employed where the advertisers are the provider (business customers), and the mobile end-users are the individual consumers. However, the principle of value co-creation and value fusion theory [77] are achieved as the value created for the entire network of consumers and firms simultaneously [78], [79]. To illustrate this, the advertisers have the value of delivering their ads more effectively, and with real-time feedback, $\mathrm{MNO}$, creating a new revenue stream and enhancing current services, and the end-user receives the incentives and ads more conveniently. Furthermore, combining advertising with data analytics would achieve the value constellation theory, wherein this theory, the principle of adding service offering to other complementary services would escalate its value rather than offering the isolated service [80]. Relevantly, in this study, offering data alone or advertising alone would be less effective than adding them together. In sum, the value becomes more superior to ever before, for all platform participants.

3) Data Source: What Data do We Require and Where Are We Going to Acquire It From? The data acquisition and data generation are the two core activities in this stage. Even though the telecommunication sector is depending to a large extent, on self-generated data by their customer touching points [43], however, in the proposed artifact, the data will also be considered a self-generated data when the platform become available and working.

In the context of DDBM [68], sources of data have been divided into:

- Internal sources of data, which are not limited to preexisting data, but rather on crowdsourced data and generation of product or service-related data.

- External sources of data such as open data, social media data, and web-crawled data, which are freely available, and other sources of data that needs to be paid for.

The crowdsourcing technique could be used to acquire more relevant data from the platform during the end-users' interaction to avoid any privacy issue. The data collected are analyzed in an aggregated format. This data will be used for 
two generic pre-defined purposes: advertising feedback and marketing insights as we have discussed earlier.

4) Key Activities: How Are We Going to Utilize this Data? To reveal the real value of data, the organization should determine the method of data processing to employ. In other words, how data analytics can generate value propositions. We previously found that data analytics could be of vital importance if it is analyzed purposefully. In the previous section, we determined that the self-generated data using crowdsourcing tools and techniques would be suitable to the proposed artifact. However, how exactly the artefact be will analyze as it is generated from the platform, is the question that will be answered at this stage. In the previous sections, our assumption has been made based on the capability to collect relevant data about the end users' spatiotemporal data and user interaction with the mobile application. The question of how these data were captured and analyzed, using what technique is relevant to this stage of the study? However, this data-driven analytics could be generated by using a particular technique that utilizes smartphone-embedded sensors. Sensors on (or attached to) mobile phones can enable attractive sensing applications in different domains, such as environmental monitoring, social networking, healthcare, transportation, and others [81].

In this vein, the new concept of mobile sensing as a service (S2aaS) has been introduced [82]. While this concept was proposed and implemented as a standalone application, to aid in data collection about users and their surrounding environment, nevertheless, The principles of exploiting sensing capabilities, of a smartphone to collect data could be attached to the advertising platform. In other words, these sensors can be programmed to be interactive buttons, where the sensor can record the user's interaction with the application while they are on the go.

By doing that, the application crowd sources the user's data using the same principle of participatory crowdsourcing, where the data, contributed from multiple participants can be combined to build a spatiotemporal view of the phenomenon of interest and also to extract key community statistics [83]. Not only spatiotemporal data, but also other interaction data, such as ad views, contact method, comments and entries, and so on. Converting all these data to visual charts that connects different variables, would generate both information about mobile advertising and insights about marketing activities.

5) Revenue Model: How can we monetize it? In simple words, it represents the quantifiable benefits that the firm attains in compensation for the value created (value proposition) for their customers. In digital platforms, the revenue model could be more complicated and BM dependent. In other words, we cannot apply the same revenue models from one platform to another because it is successful. The academic work is very shallow regarding this issue. While seven revenue streams in DDBM based on their multiple case study of start-ups was documented [68], that does not mean those revenue models are exclusive, but there might be other revenue streams that could emerge or deploy differently. Their research also has not shown how the BM designer could choose from them or based on what criteria. Another study did the same when determining the prevailing revenue models for data-driven services [74]; some of the selection criteria for each one are provided. Notwithstanding, they found that in the early stages of this kind of BM, the companies have not yet developed revenue models. While start-ups use the basic revenue models such as subscription, advertising, usage fees, and others, they observed that the new two-sided revenue models developed new elements, such as pay with data.

In this study, we are talking about mobile advertising as a media that is self-evident and would be the major revenue stream. Therefore, the persisted problem is relevant to the data analytics service offered to advertisers, as well as whether to charge end-users or not. The possibility here is to charge subscription fees or usage fees for using these services, or it could be a combination of multiple revenue models. This will be a question to be answered in the next iterations and future works. For end-users, we argue that the end-users not only should be subsidized, but also proper incentives such as monetary incentives and informational incentives should be given to them to attract them to join and create a cross-side effect. Thus, resemble the successful OTT players inside the mobile ecosystem such as Facebook, Google, and others who incentivize regular users to entice them to join and mostly, they pay with their deluge of data as regards their whereabouts just as we mentioned in pay with a data example in a framework [74].

In sum, determining the revenue model might be mysterious at this stage. Hence, we suggest that the focal firm (MNO) could adopt multiple revenue models for advertisers. The advertising model is an obvious one. Other models could be proposed based on the focal firm's and advertisers' perceptions, whereas end-users will be subsidized and incentivized but pay with their data in return. The detailed revenue model and given incentives must be determined based on stakeholders' perspectives.

6) Inhibitors: What are the Barriers to us accomplishing Our Goal? In general, the established organizations have three kinds of barriers that might hinder the development of DDBM and services, i.e., cultural issues, data quality or integrity issues, and perceived value or benefits of DDBM [43]. For example, in the telecommunication industry, two major obstacles have been defined, namely; cultural issue and data privacy [43]. The AT\&T Company, one of the pioneers in leveraging big data internally and externally was faced with these challenges at the beginning. After a short period, the company members realized the significance of big data deployment, and the culture becomes conducive to its benefits. With regards to the data privacy issue, the company starts to develop some data-driven service by using anonymous data [84].

Currently, MNOs are less affected by the cultural issue, as there is increasing awareness permeated among their members. The data privacy is problematic, only if the customers' data are identified as revealing or compromised by none opted to use. In this study, we considered these issues; the assumptions here are that the increased awareness of big data has overcome the cultural matters inherited with big data deployment. Also, the privacy issues are solved with the idea of utilizing these data, to generate insights with aggregated (anonymous) form. However, more investigation 
should be conducted to assure that these assumptions with relevant stakeholders are confirmed.

Through our analyzed literature review, the platform type $\mathrm{BM}$ is not created as a black box. Several considerations have to be considered in the development of any BM, and they include, the external environment of the platform which has a major influence on the success and design of BM components. Thus, in the next section, we extracted fundamental requirements that can be used to guide, test, and evaluate the resulted BM.

\section{Architectural Requirements of A Two-Sided Platform, Supporting Hybridisation $d f$ DDBM and Mobile Advertising}

In this section, we developed the table of requirements based on themes generated from the literature review analysis. The major themes or codes are presented in Table VI. The three main constructs include BM and two-sided BM, mobile advertising, and DDBM are deployed as selective codes to guide the synthesizing process.

TABLE VI

PROPOSED BM REQUIREMENTS

\begin{tabular}{|l|l|}
\hline Construct & Requirements (Propositions) \\
\hline BM and Two- & $\begin{array}{l}\text { - } \text { Platform thinking to compete in the mobile } \\
\text { ecosystem }\end{array}$ \\
- Shift from value chain to value network \\
- Exploit and seize new technology to form \\
new BM \\
- Convert new technology to new Value \\
propositions \\
- Adapt to market and customer requirements \\
- Adapt their new BM to their core \\
competencies. Build on current established \\
business activities and customers base
\end{tabular}

The initial fundamental requirements emerged from our literature analysis is constituted from a set of themes or codes which were translated into propositions. The selective codes or constructs are chosen based on the related conceptual framework, which consists of BM and two-sided platform, Mobile advertising, and DDBM. Within each construct, a set of relevant propositions are listed. For instance, in BM and Two-sided platform construct the proposition that the MNO to compete in the mobile ecosystem should adopt a two-sided BM thinking by utilizing new technologies to create new value propositions and shift their traditional thinking in building a new BM from value chain to value network. Another proposition the new BM should adapt to customer expectation and requirements, assembled on their core competencies and limited to current business activities and customers base. In mobile advertising, the proposition that the MNOs can better utilize the mobile advertising potential if they fulfill the advertisers' feedback requirements and provide the customer with proper incentives and data privacy and security.

Eventually, in DDBM, the external deployment of big data has high potential if the MNOs apply analogies from other industries, apply brand extension strategy, and bound it to the current value chain structure. The last resulted proposition is that Crowd data are precious to create value propositions to MNO customers if it purposefully analyzed and presented in aggregate format. However, these set of propositions are considered as a backbone of current solution-based artifact development and, represents the theoretical foundation of it.

\section{CONCLUSION}

In this paper, we proposed two-sided BM as a solution to the problems MNOs face because of their currently inferior value propositions, which are the main component of BM architecture. This proposed BM helps in solving advertisers' needs for a feedback apparatus for their advertising and marketing activities, and it also provides end-users with conventional features, characteristics, and incentives to increase their adoption of mobile advertising. These all were achieved by utilizing big data analytics as a service, sensing as a service, and two-sided market theory. The proposed BM is built on a rigorous theoretical foundation, and it can be used as a tool to help MNOs design their two-sided DDBM.

Furthermore, the design process of our artifact using both DSRM and grounded theory generates theoretical knowledge that sets out the fundamental requirements of building similar artifacts. Eventually, this work represents the first iteration according to DSR toward building a complete real solution. The future works will concentrate on studying the actual perspectives of the three stakeholders namely MNOs, advertisers and end-users to determine the real needs in a more granular level and to build a theoretical knowledge to build similar solutions.

\section{ACKNOWLEDGMENT}

The Regional Cluster supports this work for Research and Publication Grant (RCRP-2016-002) of the "Universiti Kebangsaan Malaysia” (UKM).

\section{REFERENCES}

[1] A. Y. Hmoud, J. Salim, and M. R. Yaakub, "A Two-Sided Market Mechanisms Toward Designing a Big Data-Driven Business Model for Mobile Network Operators (MNOs)," Journal of Telecommunication, Electronic and Computer Engineering (JTEC), vol. 9, pp. 105-110, 2017. 
[2] J. Wang, J.-Y. Lai, and C.-H. Chang, "Modeling and analysis for mobile application services: The perspective of mobile network operators," Technological Forecasting and Social Change, vol. 111, pp. 146-163, 2016.

[3] J. M. a. N. Mohr. (2017, January ) Overwhelming OTT: Telcos' growth strategy in a digital world. McKinsey Quarterly [White paper].

[4] P. Kannan, "Digital marketing: A framework, review and research agenda," International Journal of Research in Marketing, vol. 34, pp. 22-45, 2017.

[5] D. J. Power, "Mobile decision support and business intelligence: an overview," Journal of Decision Systems, vol. 22, pp. 4-9, 2013.

[6] Y. Raivio, S. Luukkainen, and A. Juntunen, "Open Telco: a new business potential," in Proceedings of the 6th International Conference on Mobile Technology, Application \& Systems, 2009.

[7] V. Gonçalves, N. Walravens, and P. Ballon, "'How about an App Store?" Enablers and Constraints in Platform Strategies for Mobile Network Operators," in Mobile Business and 2010 Ninth Global Mobility Roundtable (ICMB-GMR), 2010 Ninth International Conference on, 2010, pp. 66-73.

[8] A. Hagiu, Strategic decisions for multisided platforms: MIT, 2014.

[9] P. Ballon, "Platform types and gatekeeper roles: The case of the mobile communications industry," in Summer Conference on CBSCopenhagen Business School, Denmark, 2009.

[10] H. Haddadi, P. Hui, and I. Brown, "MobiAd: private and scalable mobile advertising," in Proceedings of the fifth ACM international workshop on Mobility in the evolving internet architecture, 2010, pp. 33-38.

[11] R. Mizouni and M. El Barachi, "Mobile phone sensing as a service: Business model and use cases," in Next Generation Mobile Apps, Services and Technologies (NGMAST), 2013 Seventh International Conference on, 2013, pp. 116-121.

[12] Y. Raivio and S. Luukkainen, "Mobile networks as a two-sided platform-Case Open Telco," Journal of theoretical and applied electronic commerce research, vol. 6, pp. 77-89, 2011.

[13] A. Osterwalder and Y. Pigneur, Business model generation: a handbook for visionaries, game-changers, and challengers: John Wiley \& Sons, 2010.

[14] K. Peffers, T. Tuunanen, M. A. Rothenberger, and S. Chatterjee, "A design science research methodology for information systems research," Journal of management information systems, vol. 24, pp. 45-77, 2007.

[15] J. Venable, J. Pries-Heje, and R. Baskerville, "A comprehensive framework for evaluation in design science research," in International Conference on Design Science Research in Information Systems, 2012, pp. 423-438.

[16] A. Strauss and J. M. Corbin, Basics of qualitative research: Grounded theory procedures and techniques: Sage Publications, Inc, 1990.

[17] J. Webster and R. T. Watson, "Analyzing the past to prepare for the future: Writing a literature review," MIS quarterly, pp. xiii-xxiii, 2002

[18] S. T. March and G. F. Smith, "Design and natural science research on information technology," Decision support systems, vol. 15, pp. 251266, 1995.

[19] P. Palvia, E. Mao, A. Salam, and K. S. Soliman, "Management information systems research: what's there in a methodology?," Communications of the Association for Information Systems, vol. 11, p. 16, 2003.

[20] A. Bryant and K. Charmaz, The Sage handbook of grounded theory: Sage, 2007

[21] M. Sharf, A. N. Fayez, and B. Malaysia, "AGrounded Theory For ICT-Mediated Tacit Knowledge Transferability In MNCS."

[22] C. Urquhart, H. Lehmann, and M. D. Myers, "Putting the 'theory' back into grounded theory: guidelines for grounded theory studies in information systems," Information systems journal, vol. 20, pp. 357$381,2010$.

[23] H. Bouwman, E. Faber, T. Haaker, B. Kijl, and M. De Reuver, "Conceptualizing the STOF model," in Mobile service innovation and business models, ed: Springer, 2008, pp. 31-70.

[24] M. De Reuver and T. Haaker, "Designing viable business models for context-aware mobile services," Telematics and Informatics, vol. 26, pp. 240-248, 2009.

[25] M. M. Al-Debei and D. Avison, "Business model requirements and challenges in the mobile telecommunication sector," Journal of Organisational Transformation \& Social Change, vol. 8, pp. 215-235, 2011.
[26] A. Becker, A. Mladenow, N. Kryvinska, and C. Strauss, "Aggregated survey of sustainable business models for agile, mobile service delivery platforms," Journal of Service Science Research, vol. 4, pp. 97-121, 2012.

[27] M. M. Al-Debei, E. Al-Lozi, and G. Fitzgerald, "Engineering innovative mobile data services: Developing a model for value network analysis and design," Business Process Management Journal, vol. 19, pp. 336-363, 2013.

[28] R. Amit and C. Zott, "Value creation in e-business," Strategic management journal, vol. 22, pp. 493-520, 2001.

[29] C. Baden-Fuller and S. Haefliger, "Business models and technological innovation," Long-range planning, vol. 46, pp. 419426, 2013.

[30] H. Bouwman, M. De Reuver, S. Solaimani, D. Daas, T. Haaker, W. Janssen, et al., "Business models tooling and a research agenda," The first, vol. 25, pp. 1-28, 2012.

[31] A. Ghezzi, M. N. Cortimiglia, and A. G. Frank, "Strategy and business model design in dynamic telecommunications industries: A study on Italian mobile network operators," Technological Forecasting and Social Change, vol. 90, pp. 346-354, 2015.

[32] R. C. Basole, "Visualization of interfirm relations in a converging mobile ecosystem," Journal of Information Technology, vol. 24, pp. 144-159, 2009.

[33] C.-H. Liu and K.-C. Huang, "The Hard Decision of Mobile Operators: A Dumb Pipe or a Value-Added Service Provider," 2017.

[34] F. Limbach, "Cooperative value creation and cost reduction strategies in a disintegrated telecommunications value chain," 2015.

[35] V. Faustino and W. Picoto, "Understanding Value Co-creation in a Mobile Ecosystem-A Case Study," in ICMB, 2014, p. 6.

[36] J.-C. Rochet and J. Tirole, "Two-sided markets: an overview," IDEI working paper 2004 .

[37] R. C. Basole and J. Karla, "On the evolution of mobile platform ecosystem structure and strategy," Business \& Information Systems Engineering, vol. 3, p. 313, 2011.

[38] A. Holzer and J. Ondrus, "Mobile application market: A developer's perspective," Telematics and informatics, vol. 28, pp. 22-31, 2011.

[39] R. Xia, M. Rost, and L. E. Holmquist, "Business models in the mobile ecosystem," in Mobile Business and 2010 Ninth Global Mobility Roundtable (ICMB-GMR), 2010 Ninth International Conference on, 2010, pp. 1-8.

[40] "The Roadmap to New Telco 2.0 Business Models," STL Partners April 2011.

[41] C.-H. Chang and K.-H. Huo, "Mobile advertising: Triple-win for consumers, advertisers, and telecom carriers," in Workshop on Internet Advertising, Beijing, 2011, pp. 1-6.

[42] R. Hof. (2014, 27 August) Study: Mobile Ads Do Work - Especially In Apps. Forbes.

[43] J. Brownlow, M. Zaki, A. Neely, and F. Urmetzer, "Data and Analytics-Data-Driven Business Models: A Blueprint for Innovation," Cambridge Service Alliance, 2015.

[44] T. T. Lin, F. Paragas, and J. R. Bautista, "Determinants of mobile consumers' perceived value of location-based advertising and user responses," International Journal of mobile communications, vol. 14, pp. 99-117, 2016.

[45] eMarketer, "Driven by Facebook and Google, mobile ad market soars $105 \%$ in 2013," Emarketer, 2014.

[46] K. Li and T. C. Du, "Building a targeted mobile advertising system for location-based services," Decision Support Systems, vol. 54, pp. $1-8,2012$

[47] N. M. Fong, Z. Fang, and X. Luo, "Geo-conquesting: Competitive locational targeting of mobile promotions," Journal of Marketing Research, vol. 52, pp. 726-735, 2015.

[48] P. Grover and A. K. Kar, "Big data analytics: a review of theoretical contributions and tools used in literature," Global Journal of Flexible Systems Management, vol. 18, pp. 203-229, 2017.

[49] B. Brown, M. Chui, and J. Manyika, "Are you ready for the era of 'big data,'" McKinsey Quarterly, vol. 4, pp. 24-35, 2011.

[50] V. Morabito, "Big data-driven business models," in Big Data and Analytics, ed: Springer, 2015, pp. 65-80.

[51] H. Chesbrough, "Business model innovation: it's not just about technology anymore," Strategy \& leadership, vol. 35, pp. 12-17, 2007.

[52] O. Gassmann, K. Frankenberger, and M. Csik, "The St. Gallen business model navigator," 2013.

[53] S. Gregor and A. R. Hevner, "Positioning and presenting design science research for maximum impact," MIS Quarterly, vol. 37, 2013. 
[54] B. Kerschberg. (2014, 17 December) How Big Data, Business Intelligence, and Analytics Are Fueling Mobile Application Development. Forbes.

[55] M. W. Van Alstyne, G. G. Parker, and S. P. Choudary, "Pipelines, platforms, and the new rules of strategy," Harvard business review, vol. 94, pp. 54-62, 2016.

[56] S. LaValle, E. Lesser, R. Shockley, M. S. Hopkins, and N Kruschwitz, "Big data, analytics and the path from insights to value," MIT sloan management review, vol. 52, p. 21, 2011.

[57] J. van der Lande, "Big data analytics: Telecoms operators can make new revenue by selling data," ed: Apr, 2013.

[58] K. Zheng, Z. Yang, K. Zhang, P. Chatzimisios, K. Yang, and W. Xiang, "Big data-driven optimization for mobile networks toward 5G," IEEE network, vol. 30, pp. 44-51, 2016.

[59] J. S. L. Astrid Bohé, Jim Perkins and and J. Wright, "Winning the Intensifying Battle for Customers Next-generation customer analytics enable mobile carriers to make sense of - and profit from-a treasure trove of data," Accenture2012.

[60] J. Birkinshaw and S. Ansari, "Understanding Management Models. Going Beyond" What" and" Why" to" How" Work Gets Done in Organizations," Foss, JN, \& Saebi, pp. 85-103, 2015.

[61] C. Zott, R. Amit, and L. Massa, "The business model: recent developments and future research," Journal of Management, vol. 37, pp. 1019-1042, 2011.

[62] D. J. Teece, "Business models, business strategy and innovation," Long-range planning, vol. 43, pp. 172-194, 2010.

[63] E. Giesen, S. J. Berman, R. Bell, and A. Blitz, "Three ways to successfully innovate your business model," Strategy \& leadership, vol. 35, pp. 27-33, 2007.

[64] H. Chesbrough, "Business model innovation: opportunities and barriers," Long-range planning, vol. 43, pp. 354-363, 2010.

[65] L. Massa and C. L. Tucci, "Business model innovation," The Oxford handbook of innovation management, vol. 20, pp. 420-441, 2013.

[66] C. Baden-Fuller and M. S. Morgan, "Business models as models," Long-range planning, vol. 43, pp. 156-171, 2010.

[67] K. Frankenberger, T. Weiblen, M. Csik, and O. Gassmann, "The 4Iframework of business model innovation: A structured view on process phases and challenges," International journal of product development, vol. 18, pp. 249-273, 2013.

[68] P. M. Hartmann, M. Zaki, N. Feldmann, and A. Neely, "Big data for big business? A taxonomy of data-driven business models used by start-up firms," A taxonomy of data-driven business models used by start-up firms, 2014.

[69] J. Manyika, M. Chui, B. Brown, J. Bughin, R. Dobbs, C. Roxburgh, et al., "Big data: The next frontier for innovation, competition, and productivity," 2011.
[70] M. Bulger, G. Taylor, and R. Schroeder, "Data-Driven Business Models: Challenges and Opportunities of Big Data," 2014.

[71] R. Schüritz and G. Satzger, "Patterns of data-infused business model innovation," in Business Informatics (CBI), 2016 IEEE 18th Conference on, 2016, pp. 133-142.

[72] A. Zolnowski, J. Anke, and J. Gudat, "Towards a Cost-BenefitAnalysis of Data-Driven Business Models," 2017.

[73] T. H. Davenport, "Analytics 3.0," Harvard Business Review, vol. 91, pp. 64-+, 2013.

[74] R. Schüritz, S. Seebacher, and R. Dorner, "Capturing Value from Data: Revenue Models for Data-Driven Services," in Proceedings of the 50th Hawaii International Conference on System Sciences, 2017.

[75] A. Tiwana, Platform ecosystems: aligning architecture, governance, and strategy: Newnes, 2013.

[76] M. Morris, M. Schindehutte, and J. Allen, "The entrepreneur's business model: toward a unified perspective," Journal of business research, vol. 58, pp. 726-735, 2005.

[77] B. Larivière, H. Joosten, E. C. Malthouse, M. Van Birgelen, P. Aksoy, W. H. Kunz, et al., "Value fusion: The blending of consumer and firm value in the distinct context of mobile technologies and social media," Journal of Service Management, vol. 24, pp. 268-293, 2013.

[78] W. A. Z. W. Ahmad, M. Mukhtar, and Y. Yahya, "Exploring elements and factors in social content management for ICT service innovation," in International Conference of Reliable Information and Communication Technology, 2017, pp. 851-859.

[79] M. Mukhtar, M. N. Ismail, and Y. Yahya, "A hierarchical classification of co-creation models and techniques to aid in product or service design," Computers in Industry, vol. 63, pp. 289-297, 2012.

[80] A. C. van Riel, G. Calabretta, P. H. Driessen, B. Hillebrand, A. Humphreys, M. Krafft, et al., "Consumer perceptions of service constellations: implications for service innovation," Journal of Service Management, vol. 24, pp. 314-329, 2013.

[81] X. Sheng, J. Tang, X. Xiao, and G. Xue, "Sensing as a service: Challenges, solutions and future directions," IEEE Sensors journal, vol. 13, pp. 3733-3741, 2013.

[82] X. Sheng, X. Xiao, J. Tang, and G. Xue, "Sensing as a service: A cloud computing system for mobile phone sensing," Sensors, pp. 1-4, 2012.

[83] S. S. Kanhere, "Participatory sensing: Crowdsourcing data from mobile smartphones in urban spaces," in Mobile Data Management (MDM), 2011 12th IEEE International Conference on, 2011, pp. 3-6.

[84] N. Henke, J. Bughin, M. Chui, J. Manyika, T. Saleh, B. Wiseman, et al., "The age of analytics: Competing in a data-driven world," McKinsey Global Institute, vol. 4, 2016. 